\title{
POR QUE É MELHOR EM CASA? A PERCEPÇÃO DE USUÁRIOS E CUIDADORES DA ATENÇÃO DOMICILIAR
}

\author{
Kênia Lara Silva ${ }^{1}$, Yara Cardoso Silva ${ }^{2}$, Érika Guimarães Lage ${ }^{3}$, Patrícia Alves Paiva ${ }^{4}$, Orlene Veloso Dias ${ }^{5}$
}

\begin{abstract}
RESUMO: O objetivo foi analisar as perspectivas dos usuários sobre os atendimentos de suas necessidades pelo serviço de Atenção Domiciliar. Trata-se de estudo qualitativo, com abordagem descritiva e exploratória, realizado entre fevereiro de 2014 e julho de 2015. Participaram do estudo 15 usuários e 15 cuidadores da Atenção Domiciliar de oito municípios de Minas Gerais. Os resultados indicaram que o perfil da população atendida é majoritariamente de idosos. Os motivos de admissão são diversos e remetem à cronicidade. As equipes buscam realizar as atividades considerando as necessidades naturais e radicais dos usuários. O atendimento no domicílio é apresentado como melhor opção pelo conforto do lar, vínculo com a família e com a equipe, e pela superação quanto às barreiras de acesso a outros pontos da rede de atenção à saúde. Foi possível compreender que, na perspectiva dos usuários, o cuidar em casa apresenta novas relações que ampliam o acesso, a autonomia e a qualidade de vida do usuário.
\end{abstract}

DESCRITORES: Serviços de assistência domiciliar; Necessidades e demandas de serviços de saúde; Satisfação do paciente; Políticas de Saúde Pública; Determinação de Necessidades de Cuidados de Saúde.

\section{WHY IS IT BETTER AT HOME? SERVICE USERS' AND CAREGIVERS' PERCEPTION OF HOME CARE}

\begin{abstract}
The objective was to analyze service users' perspectives regarding the attendance of their needs by the Home Care Service. This is a qualitative study, with a descriptive and exploratory approach, undertaken between February 2014 and July 2015 . A total of 15 service users and 15 caregivers participated, from the Home Care Service of eight municipalities in the Brazilian state of Minas Gerais. The results indicated that the profile of the population attended is mainly older adults. The reasons for admission are diverse, and relate to the chronic nature of the health conditions. The team seeks to undertake the activities taking into account the service users' natural and radical needs. Attendance in the home is presented as the best option due to the comfort of the home, the link with the family and with the team, and to the fact that this overcomes the barriers to accessing other points in the healthcare network. It is possible to understand that, in the service users' perspective, care provided in the home presents new relationships which broaden access, autonomy and quality of life for the service user.
\end{abstract}

DESCRIPTORS: Home Care Services; Health Services Needs and Demands; Patient Satisfaction; Public Health Policy; Needs Assessment.

\section{¿POR QUÉ EN CASA ES MEJOR? PERCEPCIÓN DE USUARIOS Y CUIDADORES DE LA ATENCIÓNDOMICILIAR}

RESUMEN: Estudio cuyo intuito fue analizar las perspectivas de los usuarios acerca de los atendimientos de sus necesidades por el servicio de Atención Domiciliar. Es un estudio cualitativo, de abordaje descriptivo y exploratorio, realizado entre febrero de 2014 y julio de 2015. Participaron 15 usuarios y 15 cuidadores de la Atención Domiciliar de ocho municipios de Minas Gerais. Los resultados apuntaron que el perfil de la población atendida es de ancianos en mayoría. Los motivos de esa opción son variables y se asocian a la cronicidad. Los equipos buscan realizar las actividades considerando las necesidades naturales y radicales de los usuarios. El atendimiento en domicilio es presentado como mejor opción a causa del conforto del hogar, vínculo con la familia y con el equipo, además de la superación de dificultades de acceso a otros puntos de la red de atención a la salud. Se constató que, en la perspectiva de los usuarios, cuidar en casa presenta nuevas relaciones que extienden el acceso, la autonomía y la cualidad de vida del usuario. DESCRIPTORES: Servicios de asistencia domiciliar; Necesidades y demandas de servicios de salud; Satisfacción del paciente; Políticas de Salud Pública; Determinación de necesidades de cuidados de Salud.

${ }^{1}$ Enfermeira. Doutora em Enfermagem. Docente de Enfermagem da Universidade Federal de Minas Gerais. Belo Horizonte, MG, Brasil.

${ }^{2}$ Gestora de Serviços de Saúde. Doutoranda em Enfermagem. Universidade Federal de Minas Gerais. Belo Horizonte, MG, Brasil.

${ }^{3}$ Gestora de Serviços de Saúde. Mestranda em Enfermagem. Universidade Federal de Minas Gerais. Belo Horizonte, MG, Brasil.

${ }^{4}$ Enfermeira. Mestranda em Ciências da Saúde. Universidade Estadual de Montes Claros. Montes Claros, MG, Brasil.

${ }^{5}$ Enfermeira. Doutora em Enfermagem. Docente de Enfermagem da Universidade Estadual de Montes Claros. Montes Claros, MG, Brasil.

Autor Correspondente:

Recebido: 08/12/2016

Kênia Lara Silva

Universidade Federal de Minas Gerais

Finalizado: 02/10/2017

Av. Alfredo Balena, 190 - 30130-100 - Belo Horizonte, MG, Brasil

E-mail: kenialara17@gmail.com 


\section{INTRODUÇÃO}

O envelhecimento populacional, a transição epidemiológica e a crise do modelo de atenção à saúde têm exigido esforços dos gestores e profissionais de saúde no intuito de buscar alternativas efetivas para atender às necessidades de saúde da população. Frente a esta demanda, aponta-se a atenção domiciliar, definida por "ações de promoção à saúde, prevenção e tratamento de doenças e reabilitação prestadas em domicílio, com garantia de continuidade de cuidados e integrada às Redes de Atenção à Saúde" (RAS) ${ }^{(1: 10)}$.

A Política Nacional de Atenção Domiciliar (AD) no Brasil foi instituída pela Portaria $n^{\circ} 2.029$ de 24 de agosto de 2011 e modificada pela Portaria do Ministério da Saúde ${ }^{\circ} 2.527$ de 27 de outubro de 2011, a Portaria $n^{\circ} 1.533$, de 16 de julho de 2012 e a seguir a Portaria $n^{\circ} 963$ de 27 de maio de 2013 que regulamentam a AD no país. Atualmente a AD é regida pela portaria $\mathrm{n}^{\circ} 825$, de $2016^{(2)}$.

A AD propõe o cuidado individualizado e contextualizado com a realidade do sujeito, sendo capaz de favorecer a recuperação da condição de saúde do usuário ${ }^{(3)}$. Receber os cuidados dos profissionais da AD pode significar, para o usuário, uma perspectiva de melhora, do prolongamento da vida com qualidade, do entendimento do seu estado clínico, além de "promover o resgate das pessoas, de suas relações com a vida, a compreensão das perspectivas futuras e a autonomia no cuidado da própria saúde" (4:183).

A participação do usuário no plano terapêutico é um diferencial entre o atendimento hospitalar e a assistência recebida em casa. A implementação do serviço contribui para o atendimento de pacientes em casa, por meio do cuidado integral e humanizado, bem como o processo de educação e promoção de saúde tanto para o paciente, quanto para a família, buscando qualidade de vida para ambos ${ }^{(5)}$.

Contudo, é escassa a literatura que discute as demais perspectivas dos usuários atendidos nos Serviços de Atenção Domiciliar (SAD). Em geral, os estudos enfatizam: autonomia do paciente; o conforto do lar; a proximidade da família e a relação com os profissionais da equipe; autoconfiança e qualidade de vida ${ }^{(5-6)}$; satisfação das necessidades ${ }^{(7)}$; e manutenção na família e na comunidade como ambiente terapêutico ${ }^{(8)}$. Visualizam-se poucos estudos que discutem as necessidades de saúde dos usuários atendidos na AD.

Neste estudo, utilizou-se o conceito de necessidade como um "desejo consciente, aspiração, intenção dirigida a todo o momento para certo objeto e que motiva a ação como tal" (9:170). Este objeto é um produto social. Diante desta conceituação, a autora apresenta dois tipos de necessidades: as naturais e as radicais. As necessidades naturais são relativas à conservação e à perpetuação da vida (alimentação, abrigo, sexual, de contato social e cooperação, relativos à autoconservação e à preservação da espécie). As necessidades radicais são as propriamente humanas e relacionam-se à liberdade, autonomia, autorrealização, autodeterminação, atividade moral e reflexão ${ }^{(9)}$.

Para discutir necessidades em saúde, adotou-se a conceituação que as classifica em: condições de vida - o modo de viver se traduz em diferentes necessidades de saúde; o acesso às tecnologias - contribui para a manutenção da saúde ou o prolongamento da vida; a criação de vínculos entre o profissional ou equipe de saúde e os usuários e os graus crescentes de autonomia que cada sujeito deve ter para conduzir sua vida ${ }^{(10)}$.

Diante do exposto, o objetivo deste estudo foi analisar as perspectivas dos usuários sobre os atendimentos de suas necessidades pelo serviço de Atenção Domiciliar.

\section{MÉTODO}

Este artigo resulta de um estudo qualitativo, do tipo descritivo e exploratório, realizado entre fevereiro de 2014 e julho de 2015. Apresenta os achados da etapa da análise de necessidades da pesquisa multicêntrica "Atenção Domiciliar em Saúde: efeitos e movimentos na oferta e demanda no SUS no Estado de Minas Gerais" desenvolvida por grupos de pesquisa de seis Universidades do Estado de Minas Gerais. 
O estudo teve como cenários os SAD de Minas Gerais, em municípios que se encontravam em conformidade com a Portaria do Ministério da Saúde $n^{\circ} 963$ de 2013 ${ }^{(11)}$ que definiu a Política Nacional de Atenção Domiciliar, por meio do Programa Melhor em Casa.

Aceitaram participar do estudo 19 municípios de Minas Gerais que ofertavam Serviços de Atenção Domiciliar vinculados ao Programa Melhor em Casa. A produção dos dados foi realizada por meio de visitas aos municípios, entrevistas com os gestores e acompanhamento do trabalho das equipes de atenção domiciliar, momento no qual foram abordados os usuários. Essa abordagem aconteceu em todos os municípios, porém em apenas oito deles houve realização de entrevistas com usuários e/ou cuidadores. Nos demais municípios, os usuários visitados recusaram participar do estudo ou encontravam-se impossibilitados de participar da coleta de dados.

Definiu-se como instrumento de coleta de dados entrevistas seguindo-se um roteiro semiestruturado com questões sobre os dados sociodemográficos (sexo, idade, escolaridade, tipo e condições de moradia, renda) e sobre o atendimento no Serviço de Atenção Domiciliar (tempo, motivo, experiência referente ao atendimento, disponibilidade de equipamentos e insumos, cuidados realizados, contato com equipe e necessidades atendidas).

O material empírico desta fase totalizou 06 horas, 15 minutos e 21 segundos de gravações, referente a 30 entrevistas: 15 com usuários e 15 com cuidadores. Cada entrevista durou em média de 18 minutos e 46 segundos. Na apresentação dos resultados, cada participante recebeu um código constituído pela letra $\mathrm{M}$ corresponde ao município (M1 a M8) e U para designar um usuário ou C para designar um cuidador.

De posse do material, foi realizada a análise de conteúdo temática, conforme Bardin ${ }^{(12)}$. Procedeuse a leitura transversal do material empírico destacando-se as unidades de registro e as unidades de significação. Os dados coletados foram analisados em categorias agrupadas analogicamente para definição destas unidades.

Os participantes foram informados e esclarecidos sobre os objetivos e finalidades do estudo, que foi aprovado pelo Comitê de Ética em Pesquisa em outubro de 2012, sob o Parecer n 129.275 .

\section{- RESULTADOS}

A análise do material empírico permitiu a emergência de duas categorias: Perfil dos usuários e as atividades realizadas no domicílio; Acesso: a Atenção domiciliar e as necessidades de saúde.

\section{Perfil dos usuários e as atividades realizadas no domicílio}

Os participantes desse estudo encontravam-se sob os cuidados de uma equipe de AD e apresentaram idades entre 38 a 89 anos. A maioria dos usuários era idosos e residiam em casa própria. Somente um usuário morava de aluguel.

Os pacientes entrevistados possuíam distintos perfis clínicos que permitiram a inclusão na Atenção Domiciliar nas modalidades AD2 e AD3, conforme normativa da área. Os motivos de admissão no SAD foram: problemas de locomoção; feridas; problemas respiratórios; uso de antibiótico; uso de suporte ventilatório; gota; e hiperêmese. As feridas e os problemas de locomoção foram os motivos de maior frequência, sendo esse último ocasionado por vários motivos: falta de força nas pernas; fratura; paciente com câncer na coluna em fase final de quimioterapia; e traumatismo de fêmur.

O tempo de atendimento domiciliar apresentou variação entre semanas e anos. Os usuários classificados no perfil de AD2 tendem a possuir permanência temporária, pois quando têm o quadro estabilizado são encaminhados para a atenção primária. No caso dos usuários enquadrados no perfil de AD3, a permanência é habitualmente contínua, decorrente das demandas clínicas.

Os achados indicam o atendimento das necessidades humanas básicas na atenção no domicílio. Estas necessidades são referentes à restauração da condição de saúde e foram mencionadas como cuidados essenciais à manutenção da vida. Neste sentido, os participantes apontam um conjunto 
de ações ligadas às atividades de vida diária (AVD) realizadas no domicílio: a higienização; banho; alimentação; troca de roupas; verificação dos dados vitais, glicemia, limpeza e troca de curativos; administração e preparo da medicação; mudança de decúbito e exercícios de fisioterapia. Os relatos que se seguem retratam esse entendimento:

A higienização, como banho, trocar os curativos, dá a medicação na hora certa e fica conversando e animando ele né [...]. (M8 C1)

Eh, faz a limpeza, a higiene, medicamento [...]. (M5 U1)

Uai, dar banho, trocar de roupa [...]. (M2 U1)

Os usuários e cuidadores são acompanhados pelos profissionais de acordo com a demanda e frequência de cuidados. A participação no plano terapêutico e a autonomia do paciente, em realizar as próprias AVD, variaram de acordo com a complexidade do caso e o envolvimento dos cuidadores. Neste sentido, os entrevistados relataram realizar algum tipo de atividade sozinho, como cuidar da própria ferida, participar do plano de cuidados e tomar as medicações. Alguns usuários relataram que recebem ajuda de outras pessoas para os cuidados diários.

[Usuário faz curativo no glúteo com o auxílio de um espelho] Eu ponho um espelho e faço... Porque aí vaza, aí a gente corta uma fralda descartável pra poder colocar, entendeu? Dar uma sugestão né porque a pessoa às vezes não tá acostumada a lidar com isso, e a gente improvisa alguma coisa. (M4 U1)

Toda a assistência, o que eu como, o que eu deixo de comer, como que eu tomo meus remédios, nas horas certas, sabe? Que hora que eu tomo a insulina, que hora que eu tomo meus remédios, tudo eles controlam direitinho, e me relembra sempre né [...]. (M2 U4).

Eles me orientaram demais com os cuidados com ele. A experiência que eu tenho hoje eu agradeço a eles. Eles quem explicaram tudo o que fazer, explicaram tudo, como que tinha que fazer os procedimentos. (M8 C2)

A equipe atua na orientação dos usuários e cuidadores. Além disso, existe a criação de vínculos entre equipe de saúde, usuários e familiares. Observou-se que a maioria conta com o apoio de cuidadores informais para o cuidado em casa. Foram identificadas a ajuda de netos, filhos, irmãs, pais, sobrinhos e vizinhos.

Os participantes reconhecem que a atuação da equipe de AD é baseada no afeto, respeito e formação de laços que contribuem para assegurar a continuidade do cuidado, por meio das orientações e treinamento dos usuários e cuidadores. Estes são elementos que compõem a dimensão do vínculo no atendimento às necessidades de saúde e se expressam nos relatos dos participantes como uma avalição positiva do serviço e dos profissionais.

O atendimento é muito bom, tanto na parte de nutricionista, fonoaudiólogo, fisioterapeuta, médico. Dá muita atenção, muita atenção mesmo ao paciente. (M1 C1)

Eles são gente muito boa, todos eles são muito carinhosos, muito atenciosos e não chegam e ficam naquela correria, naquela coisa para ir embora. Eles então param, conversam com você e tal. (M1 C2)

A equipe é muito boa, eles são muito educados, são muito atenciosos. Os enfermeiros vieram, trocaram sonda, a equipe de enfermagem toda vem/ (+) tanto os médicos quanto o fisioterapeuta. Eu não estou sozinha! (M5 C1)

Nos relatos, é possível captar o sentimento de gratidão e satisfação com o programa. Esses sentimentos estão relacionados à disponibilização de um contato telefônico para os momentos de dúvida ou intercorrência. A equipe apresenta-se disponível para o atendimento ao usuário e estabelece um sentimento de suporte e amparo para a família e o usuário. Este apoio perpassa desde a construção do plano de cuidado até o apoio e orientação em momentos de complicação ou dúvida.

\section{Acesso: a atenção domiciliar e as necessidades de saúde}

O acesso do usuário aos serviços é um elemento da dimensão estrutural do atendimento às 
necessidades de saúde. Quando este acesso é fragmentado e pontual, há desafios para o atendimento integral. Em alguns relatos, os participantes citam as dificuldades para acessar a rede de atenção à saúde, em especial os serviços de atenção básica e de urgência.

Para mim é falta de interesse mesmo sabe, porque o posto é aqui perto, menos de 5 minutos eles estão aqui, não vem porque não quer. (M6 U1)

Lá em YYY tem uma urgência já que tenho o telefone, ai eu ligo e falo: "o que que eu tenho que fazer?"(M6 U1)

Para o posto de saúde vir aqui levou dois meses. Só em dezembro que eles vieram. Aí foi agravando, agravando, a gente foi cuidando em casa né, assim, o que a gente sabe. Mas aí depois que estava bem grave que eles vieram. (M4 U1)

Por outro lado, a inserção na AD foi reconhecida pelos participantes como uma condição que facilita o acesso à rede. Assim, foram apontadas como vantagens de estar inserida no programa a facilidade com o transporte para unidades de pronto atendimento ou hospitalares, em caso de intercorrência ou piora do paciente, além de atendimento laboratorial domiciliar.

Muito, muito. É tirar sangue, se estou com dor, transporte, tudo é elas. [...] Tenho, ligo lá para a Central. [...] Qualquer coisa que eu tenha necessidade eu ligo para lá. A parte da ambulância, o transporte é muito bom também. (M6 U1)

Quando precisa colher exames, essas coisas, elas vêm aqui em casa/ o laboratório vem aqui em casa e colhe tudo certinho/ muito bem cuidado, eu não posso reclamar (M5 C2)

Quando precisa chamar eles, a gente liga e eles vem buscar e leva pro hospital. [...] Quando ele não tá na internação domiciliar e precisa ir pro hospital, aí a gente mesmo que se vira pra levar ele. (M8 U1)

Pelo o que eu vejo não é só comigo [...]. Ai esse dias eu precisei ir no médico né pra ver, pra ver se faz a cirurgia, ai eu fui com a ambulância do SAD. (M4 U1)

Então assim eles que estão sempre presentes. Eles vêm fazem exame de sangue, de urina. Eles estão sempre presentes. (M1 C1)

Ainda no que se refere ao conjunto de necessidades ligadas ao acesso aos serviços de saúde, os participantes associam a falta do atendimento assistencial e a exposição ao risco de contaminação no hospital e nas unidades de urgência como condições que foram minimizadas com a possibilidade da atenção domiciliar.

É porque eu fui lá na UAI [Unidade de urgência] eu não tinha acompanhamento nenhum. Aí a menina falou se queria que eu ficasse lá internada ou viesse pra casa. Aí eu falei: "ah então, eu vou lá pra minha casa, que é melhor né". (M3 U1)

Melhor do que ficar lá na UAI [Unidade de urgência] naquele frio, tremendo, vendo a hora de pegar uma bactéria também né. (M3 C1)

Acho que isso foi uma coisa ótima que eles criaram porque muitos não têm essas condições de ter esse privilégio de ficar em casa devido às infecções que tem nos hospitais. (M8 U2)

Em casa é muito melhor que no hospital. Porque no hospital você entra lá 24 horas, se você não tiver ninguém pra ficar com ela, você não pode sair de lá nem pra tomar um banho. Agora em casa não, eu fico aqui, eu cuido dela, eu tomo um banho, eu tomo um café, eu almoço na hora certa. (M7 C1)

Os relatos permitem reconhecer que o atendimento no domicílio é apresentado como melhor, pelo conforto do lar, vínculo com a família e com a equipe. Verifica-se que o serviço de atenção domiciliar atende as necessidades do ponto de vista histórico-filosófico-antropológico, providas pelas tecnologias leves, leves-duras e duras.

Estou muito bem acompanhada, elas têm muita atenção comigo, às vezes to num chororô danado, elas vêm e conversam comigo, puxam orelha para mim comer, porque às vezes eu não fico querendo comer né, porque a quimio mesmo em si, ela tira o paladar da gente, então aí meu filho fica inventando coisa tadinho para mim comer. (M6 U1) 
Eles me dão assistência, tem a maior preocupação comigo, sabe, nunca achei assim. [...] Agradecimento a Deus e aos serviços prestados pelos profissionais que são fundamentais, como equipe e como amigos. (M2 U4)

Nossa foi a melhor coisa que aconteceu porque o idoso a gente não pode ficar carregando de lá pra cá, de cá pra lá, você entende? (M4 C1)

Ah, eu me sinto mais confortável, né? bem mais confortável, porque ir pra médico é muito desconfortável pra mim, né? Então, eu minto saber/ a vontade, sabe? Eu fico mais sossegado, num fico preocupado (+) eu sei que e/ eu estou sendo bem cuidado, né? (M5 U1)

A equipe fornece insumos, equipamentos e medicamentos. O rol de inclusão destes varia de acordo com o proposto por cada município. No entanto, alguns gastos recaem sobre a família, mas isso não representou impedimento para a manutenção na AD.

Os materiais e as coisas como suporte de soro eles sempre disponibilizam quando eles tão vindo aqui e quando não vem mais, a gente arruma um pouco com o PSF, mas é muito pouco. (M8 U1)

Foi o médico né, eles indicaram, e a prefeitura que arrumou pra mim. Agora o bipap meu menino que comprou pra mim. Eles fizeram uma vaquinha lá e compraram o bipap pra mim. (M2 U4)

Esses dias pra trás tava sem material: Aí eu comprei, eu comprava (+) (+) mas a gente não dá conta de comprar porque é muita gazinha (+) hidrogel também, hidrogel não tinha na rede pública/ que ele tava precisando usar (+)(+) Aí nós compramos uma vez. (M5 C2)

Não se pode negar o aumento dos gastos com o paciente, sejam eles diretos ou indiretos, ao serem inseridos no atendimento domiciliar. Estes gastos compõem a dimensão das condições de vida na taxonomia das necessidades de saúde e são decorrentes do uso de medicamentos, dietas, insumos para o cuidado em sua maioria de caráter crônico.

\section{DISCUSSÃO}

Os resultados do estudo indicam que o perfil da população atendida na atenção domiciliar remete a um público mais idoso, o que requer maior tempo de internação considerando a fragilidade da saúde. Para este tipo de paciente, a presença a atuação do cuidador é considerada fundamental.

$\mathrm{Na} A D$, o cuidador com vínculo familiar é o ator responsável por prover assistência no domicílio, em um modelo denominado de sistema informal de cuidados, que está associado ao vínculo cuidadorusuário(13-14). Esta relação de cuidado possui como característica a realização do cuidado não-profissional, exercido sem remuneração por pessoas da família e amigos para a execução das atividades ${ }^{(14-15)}$.

A equipe atua na orientação dos usuários e cuidadores estabelecendo vínculos entre a equipe de saúde, usuários e familiares. Observou-se que a maioria conta com o apoio de cuidadores informais (netos, filhos, irmãs, pais, sobrinhos e vizinhos). Quando realizada associação das condições de vida com o contexto do cuidado ao usuário em $\mathrm{AD}$, nota-se que a orientação, o apoio, o vínculo, amparo e o lar assumem um sentido de atendimento às suas necessidades de saúde, o que transmite aos usuários sensação de segurança e cuidado.

Os achados indicam que as ações realizadas no domicílio visam a atender as necessidades humanas básicas proporcionando conforto, satisfação e restabelecendo o equilíbrio das funções biopsicofisiológicas. Estas necessidades são essenciais à manutenção da vida e comuns a todos os indivíduos. Contudo, a forma de satisfazê-las depende do contexto de inserção dos sujeitos e sua abordagem não se esgota na dimensão individual|(16).

A satisfação com o cuidado prestado no domicílio revela uma face das necessidades que se refere à própria realização da condição humana, que precisa de afeto, abrigo, carinho e proteção. Neste sentido, pode-se afirmar que o SAD contribui para satisfazer as necessidades naturais do usuário que implicam para além da recuperação da saúde - condição para a sobrevivência - em atingir a dimensão do ser natural. Compreende-se que o trabalho no SAD é parte de uma complexidade do trabalho humano na busca da satisfação das necessidades ${ }^{(17)}$. 
Os resultados desse estudo permitem apreender que o SAD tem adotado um processo de trabalho que abrange a ideia de suprir as necessidades de saúde da população atendida, tal como as demais necessidades humanas. As necessidades de saúde são social e historicamente determinadas. Situamse entre natureza e cultura, ou seja, não dizem respeito tão somente à conservação da vida, mas à realização de um projeto em que o indivíduo, ponte entre o particular e o genérico, progressivamente humaniza-se ${ }^{(17)}$. Como prática social, o cuidado organiza-se para atender às necessidades de saúde. Entretanto, as práticas de cuidado podem ou não corresponder às necessidades concretas dos grupos sociais.

No caso especifico da AD, os resultados indicam que os serviços têm organizado seus processos de modo a atender parcialmente as necessidades de saúde. A parcialidade deve-se à pouca capacidade dos serviços de se articular com os demais pontos da rede, de forma a garantir um complexo de ações para responder às necessidades de ter "boas condições de vida"; ter acesso e se poder consumir toda tecnologia de saúde capaz de melhorar e prolongar a vida; criar vínculos (a) efetivos entre cada usuário e uma equipe e/ou um profissional e proporcionar que cada pessoa tenha graus crescentes de autonomia no seu modo de levar a vida.

No que se refere ao acesso, destacou-se a sua compreensão como um processo que vai além do número de serviços existentes e da acessibilidade aos diversos níveis da rede de atenção. Ele inclui a qualidade do cuidado prestado, por meio de um atendimento humanizado, acolhedor de forma rápida e oportuna ${ }^{(18-19)}$.

Neste sentido, os resultados indicam que a satisfação das necessidades dos usuários tem relação com o acesso a demais pontos da rede de atenção. A entrada no SAD é visualizada, na perspectiva de usuários e cuidadores, para evitar as barreiras de acesso, em especial para os serviços de diagnóstico e de consultas especializadas. Assim, é Melhor em Casa, porque ele (o Programa) abre as portas para outros pontos da rede. O usuário do programa torna-se, então, diferenciado do conjunto dos usuários do sistema de saúde.

Os achados indicam que satisfazer as necessidades de saúde supõe o acesso às tecnologias, tanto as que remetem aos equipamentos e insumos quanto as que indicam a leveza das relações estabelecidas no cuidado domiciliar. Essas últimas são representadas nos dados pela referência aos vínculos, acolhimento, escuta e presteza que as equipes produzem junto aos usuários e cuidadores. Esse conjunto de tecnologias é utilizado na mediação do trabalho na $A D$, resultando num campo intermédio que contribui para satisfazer tanto as necessidades naturais (contato social e cooperação) quanto as necessidades radicais (autonomia, autorrealização, reflexão, entre outras).

Para a enfermagem, é importante reconhecer que o tema das necessidades deve ser um orientador central das ações e analisador das práticas em saúde. Os serviços de saúde que se organizam com foco nas necessidades da população tendem a ser mais eficientes, ao permitir a complementaridade entre aspectos objetivos e subjetivos que são valorizados, além da expressão, pelos sujeitos, dos significados atribuídos aos seus modos de vida, saúde e sofrimento ${ }^{(20)}$.

Com este entendimento, pensar a questão das necessidades em saúde e o modo como orientam o trabalho nesse campo requer reposicionamento dos sujeitos envolvidos neste processo, para uma compreensão ampliada dos desejos e das expectativas quanto aos serviços de saúde. Assim, a relação de equilíbrio entre oferta, demanda e necessidades é um pressuposto para repensar que em casa é Melhor a depender do modo como organizamos essa tríade.

Admite-se a limitação deste estudo que não incluiu, nesta fase, a investigação junto aos profissionais das equipes, sendo importante a realização de outras investigações para ampliar a perspectiva destes atores.

\section{- CONCLUSÃo}

Os achados do estudo sugerem que os serviços de atenção domiciliar têm contribuído para atender as necessidades dos usuários, sejam aquelas vinculadas à tipologia dos serviços de saúde ou mesmo as necessidades humanas naturais e radicais. Essa afirmação é evidenciada nos serviços analisados e compreende-se que pode ser aplicada a outras realidades cujas características são similares aos 
cenários do estudo.

A AD assinala-se como importante ponto da rede de atenção à saúde para os usuários e cuidadores apesar dos desafios estruturais para o pleno atendimento às demandas que se apresentam no cuidado domiciliar.

É importante destacar o reconhecimento da AD como possibilidade de superar as dificuldades de acesso a outros pontos da rede, indicando que ela atende a um conjunto de necessidades referentes à oferta de cuidado. Assim, estar na $A D$ é facilitador de um atendimento em outros pontos da rede, seja para os propósitos diagnósticos-terapêuticos, ou ainda para garantir transporte e insumos para o cuidado continuado.

Assim, foi possível compreender que é Melhor em Casa porque não se trata apenas da configuração de um novo espaço de cuidado, mas, sobretudo, de novas relações que ampliam o acesso, a autonomia e a qualidade de vida do usuário. Reafirma-se que a AD ainda precisa ser consolidada e ter o seu papel reconhecido como modalidade de atenção potente, que produz outras formas de cuidar focadas nas necessidades dos usuários e por isso, produtora de autonomia.

\section{AGRADECIMENTOS}

Agradecimentos ao Conselho Nacional de Desenvolvimento Científico e Tecnológico e a Fundação de Amparo à Pesquisa do Estado de Minas Gerais pelo auxílio financeiro e concessão de bolsas.

\section{REFERÊNCIAS}

1. Ministério da Saúde (BR). Secretaria de Atenção à Saúde. Departamento de Atenção Básica. CoordenaçãoGeral de Atenção Domiciliar. Caderno de atenção domiciliar. Brasília (DF): Ministério da Saúde; 2012.

2. Brasil. Portaria n. 825, de 25 de abril de 2016. Redefine a Atenção Domiciliar no âmbito do Sistema Único de Saúde (SUS) e atualiza as equipes habilitadas. Diário Oficial da União, Brasília, 26 abr 2016. Seção 1.

3. Favero L, Mazza VA, Lacerda MR. Home care nurse's experiencing transpersonal care to a family of a neonate discharged from an intensive care unit: case study. Online Braz J Nurs. [Internet] 2010;9(1) [acesso em 18 mai 2016]. Disponível: http://dx.doi.org/10.5935/1676-4285.20102707.

4. Feuerwerker LM, Merhy EE. A contribuição da atenção domiciliar para a configuração de redes substitutivas de saúde: desinstitucionalização e transformação de práticas. Rev Panam Salud Publica. [Internet] 2008;24(3) [acesso em 09 fev 2017]. Disponível: http://dx.doi.org/10.1590/S1020-49892008000900004.

5. César VCG. Relações de cuidado entre usuários e profissionais de saúde: avaliação qualitativa do serviço de atenção domiciliar [dissertação]. Recife (PE): Universidade Federal de Pernambuco, Programa de Pós-Graduação Integrado em Saúde Coletiva; 2014.

6. Schimith MD, Simon BS, Brêtas ACP, Budó MLD. Relações entre profissionais de saúde e usuários durante as práticas em saúde. Trab. educ. saúde (Online). [Internet] 2011;9(3) [acesso em 09 fev 2017]. Disponível: http:// dx.doi.org/10.1590/S1981-77462011000300008.

7. Alves MS, de Araújo MCF, de Castro RR, Rebouças PT, de Castro GE, Santana MVF, et al. Satisfação dos Usuários do Programa Medicamento em Casa em uma Equipe de Saúde da Família em Município Baiano. UNOPAR Cient Ciênc Biol Saúde. [Internet] 2015;17(3) [acesso em 09 fev 2017]. Disponível: http://pgsskroton.com.br/seer/index. php/JHealthSci/article/view/3061.

8. Ferreira FPC, Bansi LO, Paschoal SMP. Serviços de atenção ao idoso e estratégias de cuidado domiciliares e institucionais. Rev. bras. geriatr. gerontol. [Internet] 2014;17(4) [acesso em 09 fev 2017]. Disponível: http://dx.doi. org/10.1590/1809-9823.2014.13053.

9. Heller A. Teoria de las necessidades en Marx. Barcelona: Ediciones Península; 1986.

10. Cecílio LC. As necessidades de saúde como conceito estruturante na luta pela integralidade e equidade 
na atenção em saúde. In: Pinheiro R, Mattos RA (org.). Os sentidos da integralidade na atenção e no cuidado à saúde. $4^{a}$ ed. Rio de Janeiro: IMS-UERJ/CEPESC/ABRASCO; 2006.

11. Brasil. Portaria 963, de 27 de maio de 2013. Redefine a Atenção Domiciliar no âmbito do Sistema Único de Saúde (SUS). Diário Oficial da União, Brasília, 27 mai 2013. Seção 1

12. Bardin L. Análise de conteúdo. 7ª ed. Lisboa: Edições 70; 2011.

13. Freitas IBA, Meneghel SN, Selli L. A construção do cuidado pela equipe de saúde e o cuidador em um programa de atenção domiciliar ao acamado em Porto Alegre (RS, Brasil). Ciênc. saúde coletiva. [Internet] 2011;16(1) [acesso em 09 fev 2017]. Disponível: http://dx.doi.org/10.1590/S1413-81232011000100032.

14. Carvalho DP, Toso BRGO, Viera CS, Garanhani ML, Rodrigues RM, Ribeiro LFC. Caregivers and implications for home care. Texto Contexto Enferm. [Internet] 2015;24(2) [acesso em 09 fev 2017]. Disponível: http://dx.doi. org/10.1590/0104-07072015000782014.

15. Olanda KKR, Passos XS, Dias CS. Perfil das morbidades dos cuidadores informais de idosos com Alzheimer. J Health Sci Inst. [Internet] 2015;33(1) [acesso em 09 fev 2017]. Disponível: https://www.unip.br/comunicacao/ publicacoes/ics/edicoes/2015/01_jan-mar/V33_n1_2015_p83a88.pdf.

16. Oliveira DC. A categoria necessidades nas teorias de enfermagem: recuperando um conceito. Rev. enferm. UERJ. 2002;10(1):47-52.

17. Heller A. Una revision de la teoria de las necesidades. Barcelona: Ediciones Paidós; 1996.

18. Corrêa ACP, Ferreira F, Cruz GSP, Pedrosa ICF. Acesso a serviços de saúde: olhar de usuários de uma unidade de saúde da família. Rev. Gaúcha Enferm. [Internet] 2011;32(3) [acesso em 09 fev 2017]. Disponível: http://seer. ufrgs.br/RevistaGauchadeEnfermagem/article/view/16593.

19. Merhy EE, Magalhães JHM, Rimoli J, Franco TB, Bueno WS. O trabalho em saúde: olhando e experienciando o SUS no cotidiano. $2^{\text {a }}$ ed. São Paulo: Hucitec; 2006.

20. Hino P, Ciosak SI, da Fonseca RMGS, Egry EY. Necessidades em saúde e atenção básica: validação de instrumentos de captação. Rev. esc. enferm. USP. [Internet] 2009;43(n.esp2) [acesso em 29 jun 2017]. Disponível: http://dx.doi.org/10.1590/S0080-62342009000600003. 